Daneben hält das Thema Building Information Modeling (BIM) ebenfalls Einzug in den Kontext der 3D-Stadtmodelle. Beiträge zum Datenschutz und zur Qualitätssicherung runden das Programm ab. Wie inzwischen guter Brauch, gibt es am Ende des Workshops einen Blick in benachbarte Länder unter den Stichworten "urban planning" und "future cities".

Anmeldeformular und Flyer sind hier zu finden http://www.3dstadtmodelle.org/index.php? do=3dws 2016

\title{
Persönliches
}

\section{Ehrendoktorwürde für István Klinghammer}

Im Mai dieses Jahres erhielt István Klinghammer, emeritierter Professor der Eötvös-LorándUniversität Budapest, die Ehrendoktorwürde. Prof. Klinghammer, der am 10. August 2016 seinen 75. Geburtstag beging, kann auf ein sehr erfolgreiches Lebenswerk zurückblicken. 1987 wurde er zum ordentlichen Professor des Lehrstuhls für Kartenwissenschaft an der Eötvös-LorándUniversität ernannt und baute diesen Lehrstuhl, der mehrere Jahre lang zuvor fachlich fremdbesetzt war, sukzessive zu einem Lehrstuhl mit Institutscharakter aus. Diese Einrichtung wurde somit eine international anerkannte Ausbildungs- und Forschungsstätte der Kartographie. Besonders hervorzuheben, dass Prof. Klinghammer rechtzeitig institutionelle Konsequenzen aus dem Paradigmenwechsel der Kartographie ableitete. Er überführte 2003 seine Einrichtung von der Naturwissenschaftlichen Fakultät zu der Informatik-Fakultät. Der Lehrstuhl wurde in „Kartenwissenschaft und Geoinformatik" umbenannt. Dabei wurden jedoch die Prinzipien der „traditio-

Kalender 2017 vom LGB Durchs Jahr 2017 mit Abbildungen aus „Mein Platz im Land Brandenburg"

Aus den Bildern des Schülerwettbewerbs „Mein Platz im Land Brandenburg “ (KN 4/2016) wurde der Kalender 2017 gestaltet. Dieser kann ab sofort über den GEOBROKER der Landesvermessung und Geobasisinformation (LGB) bestellt werden. Weiterführende Informationen erhalten Sie auch über die Produktseite im Internet http://www.geobasis-bb. de/geodaten/kalender.htm."

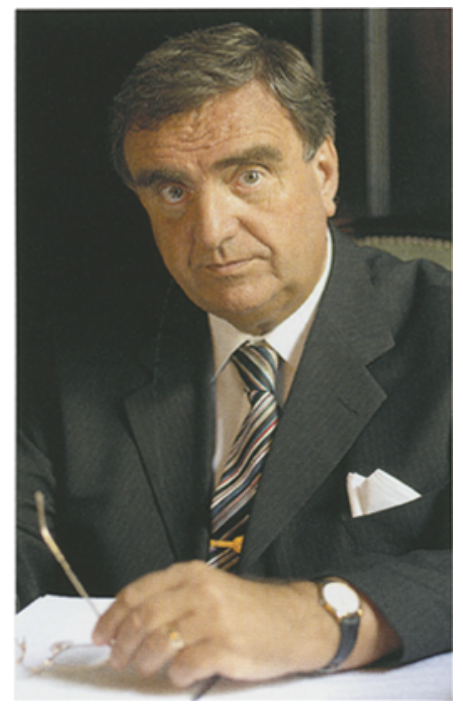

István Klinghammer

nellen“ Kartographie keineswegs aufgegeben, sondern weitergepflegt und mit den neuen Möglichkeiten der Kartographie als angewandter Informatik bereichert. Darüber zeugen $u$. a. auch die Publikationen von Prof. Klinghammer. Er verfasste vierzehn Bücher und über hundert Studien in Sammelwerken bzw. Zeitschriften. Prof. Klinghammer übte zahlreiche akademische Leitungsfunktionen aus, so z. B. war er von 2000 bis 2006 Rektor der Eötvös-Loránd-Universität, von 2010 bis 2013 war er Präsident des Kuratoriums der deutschsprachigen Gyula-Andrássy-Universität. 2013 wurde Prof. Klinghammer zum Staatsekretär an das Kultusministerium berufen. Durch seine diesbezügliche Tätigkeit wurde er einer der bekanntesten Politiker in Ungarn, da er eine äußerst schwierige Problematik in der ungarischen Hochschulpolitik, auch durch Ausarbeitung neuer Gesetze, bewältigen konnte. In seinen sämtlichen Leitungsfunktionen erwies er sich zur Lösung von Konfliktsituationen durch seine Charaktereigenschaften, wozu ein groBes Organisationstalent, aber auch der Humor gehörte, stets als prädestiniert.

Prof. Klinghammer erhielt zahlreiche Ehrungen, u. a. die Ehrenmitgliedschaft der ICA (2005). 2000 wurde er ordentliches Mitglied der Deutsche Akademie der Naturforscher Leopoldina und 2010 ordentliches Mitglied der Ungarischen Wissenschaftsakademie. 2012 erhielt er eine der höchsten staatlichen Auszeichnungen Ungarns, das Silberne Verdienstkreuz. Mit der Verleihung des Ehrendoktortitels in diesem Jahr bekamen seine wissenschaftlichen Leistungen eine weitere gebührende Würdigung.

Gyula Pápay, Rostock

\section{- Władysław Pawlak 1931-2016}

Am 3. August 2016 ist in Wrocław (Breslau) der in seinem Heimatland weithin bekannte polnische Kartograph Władysław Pawlak verstorben. Mit ihm hat die polnische Kartographie einen hochrangigen Wissenschaftler verloren, der über Jahrzehnte im schlesischen Raum in der Verlagskartographie und an der altehrwürdigen Breslauer Universität tätig war.

Geboren am 26. Juli 1931 in Dobra bei Limanowa (Wojewodschaft Krakau, heute kleinpolnische Wojewodschaft) im nörd- lichen Vorland von Gorce-Gebirge und Hoher Tatra, begann er 1951 ein Geographiestudium an der Fakultät für Biologie und Geowissenschaften der Universität Krakau, das er an der Universität Breslau fortsetzte und 1955 als Magister der Geographie mit dem Vertiefungsfach Kartographie abschloss. Die Hauptstadt Niederschlesiens blieb fortan sein Wohnsitz und Arbeitsort. Hier fand er Mitte der 1950er Jahre, als auch in unserem östlichen Nachbarland vieles im Neuaufbau war und kartographische Erzeugnisse für Allgemeinbildung, Schule, Wirtschaft, Wissenschaft $u$. a. $m$. benötigt wurden, seine erste Arbeit als Kartograph im Betriebsteil Breslau des 1951 neu gegründeten staatlichen kartographischen Betriebes Państwowe Przedsiębiorstwo Wydawnictw Kartograficznych (PPWK) Warszawa-Wroctaw. Dieser Betriebsteil war die 1924 von Eugeniusz Romer (18711954) in Lemberg gegründete ehemalige Kartographische Anstalt „Książnica-Atlas“, die man bald nach dem Ende des Zweiten Weltkriegs nach Breslau verlagert hatte. Zunächst bearbeitete W. Pawlak Schulwandkarten von Nordamerika (1957, 1958). Unter seiner Redaktion wurde sodann 1964 der neue Schulatlas „Atlas geograficzny V-VII klasy" in Fortentwicklung der Romerschen Traditionen in hoher graphischer und inhaltlicher Qualität neu bearbeitet und in mehreren hohen Auflagen herausgegeben. Ihm folgten die ersten Regionalatlanten im Nachkriegspolen: Der

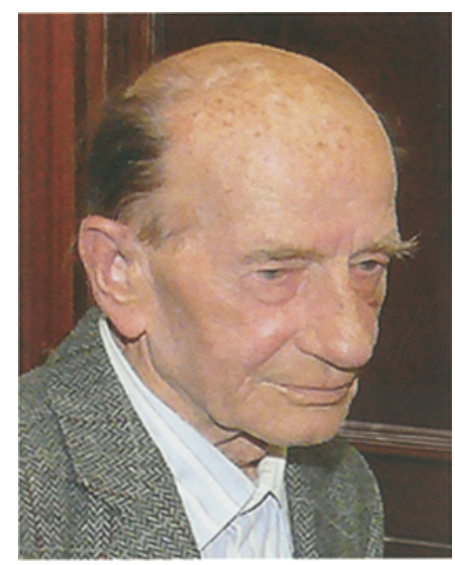

